\title{
AOR
}

Selected Papers of \#AolR2019: The $20^{\text {th }}$ Annual Conference of the Association of Internet Researchers Brisbane, Australia / 2-5 October 2019

\section{TROLLING FOR ENGAGEMENT: AUSTRALIAN LEGACY NEWS OUTLETS SEEKING AUDIENCE INTERACTION METRICS ON FACEBOOK THROUGH DELIBERATELY DIVISIVE CONTENT}

\author{
Edward Hurcombe \\ Digital Media Research Centre, Queensland University of Technology \\ Introduction
}

News-reading publics are co-evolving with dominant social media platforms such as Facebook (Nielsen \& Schroder, 2014). The operational practices of legacy news outlets are transforming in tandem with these publics, as well as in relation to platform logics (Caplan \& boyd, 2018), meaning organizational principles and algorithmic valuing regimes (van Dijck \& Poell, 2013). This paper empirically investigates how two prominent Australian news outlets - $A B C$ News and News.com.au - operate according to what I term a social media logic of "engagement", a concept which builds upon van Dijck \& Poell's notion of a social media logic of "popularity" (2013). Focusing on the operations of these outlets on Facebook within a period of three weeks in early 2018, these findings suggest that outlets pursuing engagement can act in deliberatively divisive ways. Such divisive practices should be considered as a form of trolling: deceptive and faux-naïve actions seeking discord in online spaces.

\section{Background}

The "logics" framework has been useful in examining the ways in which internal governing principles effect how individuals and organisations behave on platforms. Van Dijck \& Poell have previously argued that platforms are guided by a logic of "popularity", meaning the filtering processes on platforms that valued and promoted more "liked", "shared", and "followed" posts and users over others in Facebook newsfeeds. However, "popularity" does not accurately capture filtering processes on Facebook, as the platform does not value and promote that which is purely "popular". Instead, it is that which is most engaged with - the word "engaged" reflecting a multitude of feelings, sentiments, and reactions given high prominence in newsfeed hierarchies.

Facebook reaction buttons are notable indicators of a social media logic of engagement. Reaction buttons were introduced to Facebook in early 2016, following Product Design

Suggested Citation (APA): Hurcombe, E. (2019, October 2-5). Trolling for Engagement: Australian Legacy News Outlets Seeking Audience Interaction Metrics on Facebook Through Deliberately Divisive Content. Paper presented at AolR 2019: The $20^{\text {th }}$ Annual Conference of the Association of Internet Researchers. Brisbane, Australia: AolR. Retrieved from http://spir.aoir.org. 
Director Geoff Teehan declaration that "not everything in life is Likable" (2016). Facebook's shift towards multiple reactions has changed how users express themselves and how they respond to content and other users on the platform. Moreover, comments have always expressed differing reactions. Sharing content is also not necessarily an endorsement. Allowing for "Sad" or "Angry" reactions, as well comments and shares of varying sentiments, to all be quantifiable metrics that determine visibility on platforms has meant that a logic of "popularity" is not wholly accurate. It is beneficial, thus, to investigate how the need for engagement effects the practices of news outlets which are increasingly dependent on Facebook for monetizable audiences.

\section{Methods}

Manual digital methods, including close readings of select posts, were used to investigate how outlets' desire to maximize audience attention and interaction metrics effects their operations on Facebook. To do so, this research examined Facebook pages from two of Australia's largest news outlets, ABC News and News.com.au, between 21 March 2018 - 10 April 2018. This three week period was chosen because the ideas of this paper were developed around this time. Within this period, I collected all the posts from each page, which amounted to 44 posts in total. I stored screenshots and archived hyperlinks for each post in an Evernote file. One year post initial data collection, the engagement metrics for each post were tabulated and analyzed. From the 44 posts that I collected, I strategically selected six posts of varying levels of engagement for closer textual analysis (McKee, 2003) below.

This manual approach was adopted due to the limitations of Facebook's API. Attempts at using automated digital methods to collect and analyse complete post data faced difficulties. Most notably, when I tested Facebook data collection and analysis tool Netvizz (Reider, 2013), it returned incomplete post data. When preparing this paper, I also discovered that Facebook now lacks a search post function on pages, which makes it difficult to retrieve older posts from pages with high output. These difficulties raise ongoing concerns around transparency on platforms more broadly.

\section{Preliminary findings}

Two of $A B C$ News and News.com.au's most engaged posts during this period usefully illustrate the ways that the outlets sought audience attention and interaction metrics. For News.com.au, a post on 26 March 2018 reported on a recent Australian cricket scandal. It included a humorous image of the memoir of Steve Smith, then-captain of Australia's men's team, found in a book shop's "true crime" section. At the time, Smith was accused of ball-tampering. The post received over 7,500 reactions (the top three being "Like", "Haha", "Love"), over 1,400 shares, and over 2,800 comments. For ABC News, the page's most popular post during 21 March - 10 April was an Easter-themed opinion piece declaring that "Jesus wasn't white: he was a brown-skinned, Middle Eastern Jew". The post received over 4,800 reactions (top three being "Like", "Haha", and "Love"), over 1,000 shares, and over 1,180 comments. In comparison, most posts during this period received up to 100 reactions and 20 comments. 
Additional results further suggest that outlets are utilizing controversial topics in pursuing engagement. A number of other articles that I collected during this period also tapped into contemporary cultural, social, and political sites of conflict around race, gender, and environmentalism. For instance, an $A B C$ News article reported on an extreme weather event, and asked readers whether the event could be "attributed to climate change": the distanced and objective language seemingly being used to provoke doubt. Another $A B C$ News article reported that "political correctness was 'stifling Australian cinema", the post caption stating that "Australia's film industry has seemingly withdrawn into a safe space". Both "political correctness" and "safe space" are terms with considerable prominence in online right-wing discourse, their use likely intending to provoke negative sentiments. A News.com.au article reported on a blackface incident at a local football club, where a "group of blokes out on the beers" sparked "outrage" online. The "blokes" descriptor appeared to cast doubt on the offensiveness of their actions, and seemingly aimed to provoke negative feelings about the "outrage". Another News.com.au reported on a transgender athlete qualifying for a women's weightlifting event. The article quotes transphobic comments from "rival federations". The comment sections of these articles were politically combative, and, in the case of the athlete article, characterized by transphobic sentiment. These posts received varying levels of engagement.

Based on these preliminary findings, this research finds that the affordances and logics of Facebook appear to enable and encourage forms of deliberatively divisive practices when outlets pursue engagement, and therefore visibility. Although sensational and polarizing news content are not new (Phillips, 2015: 95), these practices seem to intensify and transform when users can directly react and respond to the article and to each other, and when visibility is an algorithmic reward determined by such engagement. Trolls are those that deceive other users of their intentions, and seek to sow discord for their own purposes (Phillips, 2015: 15-17). Thus, it is beneficial to think about a potentially emerging practice of news "trolling", as it appears that news outlets are adopting faux-naïve, as well as deliberately incendiary, practices in order to satisfy Facebook's logic of engagement.

\section{References}

Caplan, R., \& boyd, d. (2018). 'Isomorphism through algorithms: Institutional dependencies in the case of Facebook', Big Data \& Society, 5(1), 1-12.

McKee, A. (2003). Textual Analysis: A Beginner's Guide. London: Sage.

Nielsen, R. K. and Schrøder, K. C. (2014) 'The relative importance of social media for accessing, finding, and engaging with news', Digital Journalism, 2(4), 472-489.

Phillips, W. (2015). This Is Why We Can't Have Nice Things: Mapping the Relationship between Online Trolling and Mainstream Culture. Cambridge, MA: MIT Press.

Reider, B. (2013). 'Studing Facebook via data extraction: The Netvizz application.' WebSci '13: Proceedings of the $5^{\text {th }}$ Annual ACM Web Science Conference, pp. 346355.

Van Dijck, J., \& Poell, T. (2013). 'Understanding social media logic', Media and 
Communication, 1(1), 2-14. 